\section{Commentary: Radial artery — Try it; you might like it, and your patients will love it}

\author{
Thomas A. Schwann, MD, MBA
}

This report $^{1}$ represents the multidecade experience with radial artery (RA) in coronary artery bypass grafting $(\mathrm{CABG})$ by a pioneer and expert in this field. It is an excellent summary of the technical and practical aspects of RA use as a coronary conduit. It will serve both as an excellent guide for surgeons beginning their RA journey as well as a valuable reference for experienced surgeons.

The last decade has seen an explosion of high-quality data on the value of the RA as a second arterial conduit in internal thoracic artery (ITA)-based CABG, with documentation of both its long-term clinical benefits and safety compared with saphenous vein grafts (SVGs). In a patient-level analysis of 6 randomized prospective RA versus SVG trials, each of which individually was likely underpowered to detect clinically meaningful differences, Gaudino and colleagues ${ }^{2}$ found a significantly lower rate of adverse cardiac events and a greater patency rates at 5 years postoperatively. In a 10 -year follow up, ${ }^{3}$ RA use was associated with decreased risk of the composite of death and myocardial infarction. In another study, ${ }^{4}$ the 20 -year RA patency was $75 \%$, significantly greater than SVG and equivalent to the left ITA. In a statewide analysis, ${ }^{5}$ the use of a second arterial graft (right ITA or RA) was associated with significantly lower 7-year risk of mortality, myocardial infarction, and repeat revascularization, with no differences in outcomes between right

From the Division of Cardiac Surgery, Department of Surgery, University of Massachusetts-Baystate, Springfield, Mass.

Disclosures: The author reported no conflicts of interest.

The Journal policy requires editors and reviewers to disclose conflicts of interest and to decline handling or reviewing manuscripts for which they may have a conflict of interest. The editors and reviewers of this article have no conflicts of interest.

Received for publication Oct 3, 2020; revisions received Oct 3, 2020; accepted for publication Oct 20, 2020; available ahead of print Nov 18, 2020.

Address for reprints: Thomas A. Schwann, MD, MBA, Division of Cardiac Surgery, Department of Surgery, University of Massachusetts-Baystate, 759 Chestnut St, Springfield, MA 01199 (E-mail: Thomas.schwannmd@baystatehealth.org).

JTCVS Techniques 2021;5:60-1

2666-2507

Copyright $@ 2020$ The Authors. Published by Elsevier Inc. on behalf of The American Association for Thoracic Surgery. This is an open access article under the CC BY-NCND license (http://creativecommons.org/licenses/by-nc-nd/4.0/).

https://doi.org/10.1016/j.xjtc.2020.10.047

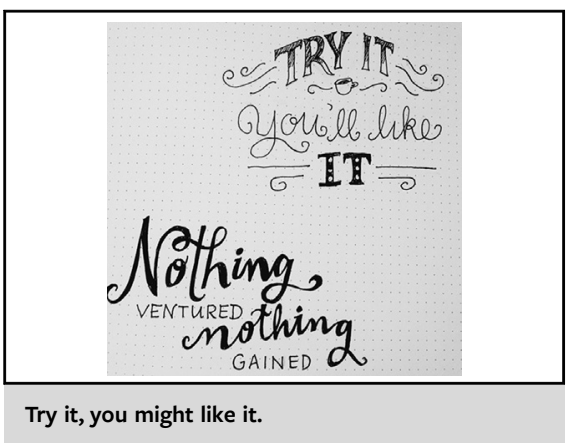

CENTRAL MESSAGE

Radial artery should be used more frequently in CABG.

ITA and RA. The safety of RA was also documented in a large nationwide analysis of the Society of Thoracic Surgeons Database of more than 1.3 million patients undergoing CABG between 2004 and 2015. ${ }^{6}$ Importantly, in contradistinction to single arterial CABG, only multiarterial RA-based CABG was associated with improved long-term survival compared with percutaneous coronary intervention. ${ }^{7}$ These data cumulatively, as well the absence of any data documenting inferior outcomes of RA versus SVG, have led to a Class I recommendation for RA use in CABG. ${ }^{8}$ Despite this evidence, the national RA use in the United States has remained persistently low, being $6.3 \%$ in the 2019 Society of Thoracic Surgeons Database.

It is hard to understand this disconnect between evidence and practice. The specific barriers to a more routine use of RA remain undefined and warrant further analysis. In the only survey of cardiac surgeons on this subject, ${ }^{9}$ the reservations expressed by surgeons were concerns of greater mortality and morbidity, prolonged operative times, and a steep learning curve. Despite this, however, only $27 \%$ of surveyed surgeons would elect to undergo a traditional single arterial-based CABG should they require a coronary revascularization. Although medical innovation proceeds at a glacial pace, cardiac surgeons have always been at its forefront. It is time for current cardiac surgeon to build on that tradition of innovation, particularly in an era of constrained medical resources and the enhanced intense search for value in health care. Our professional societies must play a more active role in this process and help facilitate the transition away from single arterial CABG to multiarterial CABG.

Dr Tatoulis's report should certainly serve as a trusted guide on this journey. 


\section{References}

1. Tatoulis J. The radial artery: An important component of multiarterial coronary surgery and considerations for its optimal harvest. J Thorac Cardiovasc Surg Tech. 2021;5:46-55.

2. Gaudino M, Benedetto U, Fremes S, Biondi-Zoccai G, Sedrakyan A, Puskas JD, et al. Radial-artery or saphenous-vein grafts in coronary-artery bypass surgery. N Engl J Med. 2018;378:2069-77.

3. Gaudino M, Benedetto U, Fremes S, Ballman K, Biondi-Zoccai G, Sedrakyan A, et al. Association of radial artery graft vs saphenous vein graft with long-term cardiovascular outcomes among patients undergoing coronary artery bypass grafting: a systematic review and meta-analysis. JAMA. 2020;324:179-87.

4. Gaudino M, Tondi P, Benedetto U, Milazzo V, Flore R, Glieca F, et al. Radial artery as a coronary artery bypass conduit. J Am Coll Cardiol. 2016;68:603-10.

5. Goldstone AB, Chiu P, Baiocchi M, Wang H, Lingala B, Boyd JH, et al. Second arterial versus venous conduits for multivessel coronary artery bypass surgery in California. Circulation. 2018;137:1698-707.

6. Schwann TA, Habib RH, Wallace A, Shahian DM, O'Brien S, Jacobs JP, et al Operative outcomes of multiple-arterial versus single-arterial coronary bypass grafting. Ann Thorac Surg. 2018;105:1109-19.

7. Habib RH, Dimitrova KR, Badour SA, Yammine MB, El-Hage-Sleiman AK, Hoffman DM, et al. CABG versus PCI. J Am Coll Cardiol. 2015;66:1417-27.

8. Neumann F-J, Sousa-Uva M, Ahlsson A, Alfonso F, Banning AP, Benedetto U, et al. 2018 ESC/EACTS guidelines on myocardial revascularization. Eur Heart J. 2019;40:87-165.

9. Catarino PA. Why do UK cardiac surgeons not perform their first-choice operation for coronary artery bypass graft? Heart. 2002;88:643-4. 